\title{
A Longitudinal Study of Relation between Side-effects and Clinical Improvement in Schizophrenia: Is There a Neuro-metabolic Threshold for Second Generation Antipsychotics?
}

\author{
Ganesan Venkatasubramanian, Naren P. Rao, Rashmi Arasappa, Sunil V. Kalmady, Bangalore N. Gangadhar \\ The Metabolic Clinic in Psychiatry, Department of Psychiatry Translational Psychiatry Laboratory, Cognitive Neurobiology Division, \\ Neurobiology Research Centre, National Institute of Mental Health \& Neurosciences [NIMHANS], Bangalore, India
}

\begin{abstract}
Objective: Classical studies demonstrated Neuroleptic Induced Extrapyramidal Side-effects (NIES; Neuroleptic threshold) to correlate with the efficacy of first generation antipsychotics. Second generation antipsychotics (SGAs), in addition to the extrapyramidal side effects, are also associated with metabolic side effects. This prospective study on antipsychotic-naïve schizophrenia patients, for the first-time, examined concurrently the relationship between clinical improvement and these side-effects NIES and Neuroleptic Induced Metabolic Side-effects.

Methods: Thirty six-antipsychotic-naïve schizophrenia (DSM-IV) patients were examined at baseline and after 5 weeks of treatment with antipsychotics. At baseline and follow-up, we recorded the body mass index (BMI) and assessed psychopathology using Scale for Assessment of Positive-symptoms (SAPS) and Scale for Assessment of Negative-symptoms (SANS), extrapyramidal symptoms using Simpson-Angus Extra Pyramidal Scale (SAEPS) and improvement using Clinical Global Impression Improvement (CGI). Results: After treatment, patients showed significant reduction in SAPS (baseline, 27.97 \pm 14.47 ; follow-up, 14.63 $\pm 13.25 ; p<0.001$ ) and SANS total scores (baseline, 63.77 \pm 28.96 ; follow-up, 49.30 $\pm 28.77 ; p=0.001$ ) and a significant increase in BMl (baseline,

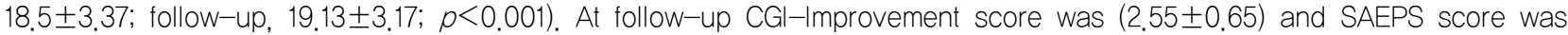
(0.8 \pm 1.32$)$. CGI-Improvement score had a significant negative correlation with magnitude of increase in $B M l\left(r_{s}=-0.39 ; p=0.01\right)$ and SAEPS symptom score at follow-up ( $\left.r_{s}=-0.58 ; p<0.001\right)$. In addition, magnitude of increase in BMl showed positive correlation with the magnitude of reduction in SAPS total score $\left(r_{s}=0.33 ; p=0.04\right)$.

Conclusion: The study findings suggest a possible relation between clinical improvement and antipsychotic-induced neuroleptic as well as metabolic side-effects in schizophrenia. Though the mechanism of this relation is yet to be elucidated, insulin signaling pathways and lipid homeostasis are potential mechanisms in addition to the established neurotransmitter hypothesis. Theoretically findings support the novel hypothetical construct of 'Neuro-Metabolic threshold' in the treatment of schizophrenia,
\end{abstract}

KEY WORDS: Schizophrenia; Antipsychotic; Metabolic; Extrapyramidal; Insulin.

\section{INTRODUCTION}

The antipsychotic efficacy of first generation antipsychotics (FGA) was shown to be associated with "neuroleptic" side effect of the drug and gave rise to neuroleptic threshold theory. According to this theory, the minimum effective dose of antipsychotic correlates with appearance of fine motor symptoms and about half of acute schizophrenia patients responded to this dose. ${ }^{1,2}$

\footnotetext{
Received: January 12, 2012 / Revised: September 20, 2012

Accepted: October 16, 2012

Address for correspondence: Ganesan Venkatasubramanian, MD Department of Psychiatry, National Institute of Mental Health and Neuro Sciences, Bangalore-560029, India

Tel: +91-80-26995256, Fax: +91-80-26564830

E-mail:venkat.nimhans@yahoo.com
}

This was supported by the findings of imaging studies which suggested a minimum of $50 \%$ D2 occupancy by antipsychotic for a clinical response and $80 \%$ striatal D2 receptor occupancy for extra-pyramidal symptoms (EPS). ${ }^{3-5)}$

On the other hand atypical antipsychotics in addition to extrapyramidal side-effect (though less than FGA) are also associated with excessive weight gain and related metabolic side effects. ${ }^{6,7)}$ Interestingly, increasing number of reports support a significant relationship between beneficial therapeutic effects and antipsychotic-induced weight gain. ${ }^{8,9)}$ Indeed, link between weight gain and favorable therapeutic response has been documented even during the era of FGA. ${ }^{10)}$ Among the atypical antipsychotics, the link between weight gain and better clinical outcome has been demonstrated for clozapine, ${ }^{8,9)}$ olanzapine ${ }^{10,11)}$ as

(c) This is an Open-Access article distributed under the terms of the Creative Commons Attribution Non-Commercial License (http://creativecommons.org/licenses/by-nc/3.0) which permits unrestricted non-commercial use, distribution, and reproduction in any medium, provided the original work is properly cited. 
well as risperidone. ${ }^{12,13)}$

However, most of these studies are post hoc analysis or retrospective studies and we are unaware of any study that has prospectively examined concurrently the relationship between clinical improvement and these side-effects Neuroleptic Induced Extrapyramidal Side-effects (NIES) and Neuroleptic Induced Metabolic Side-effects (NIMS). Thus, we, for the first time, examined concurrently the relationship between clinical improvement and NIES and NIMS in antipsychotic-naïve schizophrenia patients. We hypothesized that increase in NIMS and NIES would positively correlate with reduction in psychopathology and clinical improvement.

\section{METHODS}

Patients attending the clinical services of the National Institute of Mental Health and Neurosciences (India), who fulfilled Diagnostic and Statistical Manual of Mental Disorders (DSM)-IV criteria for schizophrenia and were never treated with any antipsychotics medications and not having substance abuse were referred by the screening clinical psychiatrist to the "Metabolic Clinic in Psychiatry" as a part of ongoing neurobiological studies in schizophrenia. Among these, 36 patients (age, 30.28 \pm 7.8 years; 25 women) who fulfilled all the study criteria (antipsychotic-naïve status at baseline, no co-morbid substance dependence, treatment with risperidone as determined by the clinician, no co-morbid chronic medical disease) are described in this report. The diagnosis of schizophrenia was established using Mini International Neuropsychiatric Interview Plus. ${ }^{14)}$ The details related to illness onset and antipsychotic-naïve status were carefully ascertained by reliable information obtained from at least two adult relatives (with minimum one being a first-degree relative/spouse). The age-at-onset of psychosis was $27.37 \pm 8.16$ years and duration of untreated psychosis was $34.72 \pm 31.08$ months. Psychosis symptoms were assessed using Scale for Assessment of Positive-symptoms (SAPS) ${ }^{15)}$ and Scale for Assessment of Negative-symptoms (SANS). ${ }^{16)}$ Body mass index (BMI; $\mathrm{kg} / \mathrm{m}^{2}$ ) was calculated for all subjects as per their weight $(\mathrm{kg})$ and height $(\mathrm{m})$. The propensity to develop diabetes mellitus was assessed in all subjects using the Simplified Indian Diabetes Risk Score (SIDRS). ${ }^{17)}$ All subjects had a SIDRS of $\leq 50$.

Patients were examined to rule out any substance dependence. None had history or clinical feature suggestive of neurological/medical disorder. None had abnormal movements as assessed by Abnormal Involuntary Move- ments Scale. Baseline clinical assessments were performed on the same day before starting antipsychotics. After complete description of study to the subjects, written informed consent was obtained. The study had the approval of the institute's ethics committee. Subsequent to baseline assessments, the patients were started on risperidone (4.05 $\pm 0.53 \mathrm{mg} /$ day). Follow-up assessments were done after about 5 weeks of treatment with antipsychotics (mean \pm standard deviation, 34.1 \pm 4.1 days). During follow-up, the patients were re-examined using the same clinical rating scales as during baseline assessments; a comprehensive account of interval history was carefully ascertained and the adherence to antipsychotic treatment was ensured as per reliable information obtained from the care-giver.

The statistical analyses were performed using the Statistical Package for Social Sciences (version 11; SPSS Inc., Chicago, IL, USA). The socio-demographic data were analyzed using the Independent samples t-test and the chi square test. Paired samples t-test was used to examine for differences between baseline and follow-up assessments. Pearson's test was used to perform correlational analyses. The statistical significance was set at $p<0.05$ (two-tailed).

\section{RESULTS}

After treatment, patients showed significant reduction in SAPS and SANS total scores (Table 1). BMI was significantly increased during follow-up assessments in schizophrenia patients (Table 1). The Clinical Global Impression Improvement (CGI)-Improvement score was $2.55 \pm 0.65$. None of them had extrapyramidal symptoms at baseline and the extrapyramidal symptom score during follow-up was $0.8 \pm 1.32$. The magnitude of increase in BMI was calculated by subtracting the baseline value from the follow-up value (i.e., Follow-up minus Baseline). The magnitude of reduction in SAPS total score was calculated by subtracting follow-up score from baseline

Table 1. Comparative profile of Schizophrenia patients at baseline and follow-up

\begin{tabular}{ccccrr}
\hline \multirow{2}{*}{ Variable } & \multirow{2}{*}{$\begin{array}{c}\text { Baseline } \\
(\mathrm{N}=36)\end{array}$} & \multirow{2}{*}{$\begin{array}{c}\text { Follow-up } \\
(\mathrm{N}=36)\end{array}$} & \multicolumn{2}{c}{ Analysis } \\
\cline { 5 - 6 } & & & $t^{*}$ & \multicolumn{1}{c}{$P$} \\
\hline SAPS score & $27.97 \pm 14.47$ & $14.63 \pm 13.25$ & 6.09 & $<0.001$ \\
SANS score & $63.77 \pm 28.95$ & $49.30 \pm 28.77$ & 3.58 & 0.001 \\
BMl $\left(\mathrm{kg} / \mathrm{m}^{2}\right)$ & $18.5 \pm 3.37$ & $19.13 \pm 3.17$ & 4.70 & $<0.001$ \\
\hline
\end{tabular}

Values are presented as mean \pm standard deviation. *Paired samples t-test.

SAPS, Scale for Assessment of Positive-symptoms; SANS, Scale for Assessment of Negative-symptoms; BMl, body mass index. 
score (Baseline minus Follow-up). The magnitude of reduction in SANS total score was calculated by subtracting follow-up SANS total score from baseline SANS total score (i.e., Baseline minus Follow-up).

The magnitude of reduction in SAPS total score showed significant positive correlation with the increase in BMI $\left(\mathrm{r}_{\mathrm{s}}=0.33 ; p=0.04\right)$ as well as extrapyramidal symptom score at follow-up ( $\left.\mathrm{r}_{\mathrm{s}}=0.37 ; p \leq 0.02\right)$. The CGI-Improvement score (the lower the score better the improvement) had a significant negative correlation with magnitude of increase in BMI $\left(\mathrm{r}_{\mathrm{s}}=-0.39 ; p=0.01\right)$ and extrapyramidal symptom score at follow-up $\left(\mathrm{r}_{\mathrm{s}}=-0.58 ; p \leq 0.001\right)$. That is higher the increase in BMI and extrapyramidal score, better was the clinical improvement.

To control for the potential confounding effects of antipsychotic dose effect, we re-analyzed the relationship between the CGI-Improvement score and the neuro-metabolic side-effect scores (i.e., extrapyramidal symptoms as well as change in BMI) using partial correlation analysis with chlorpromazine equivalence as the confounding variable. The significance of the correlations persisted even after partialling out the potential antipsychotic dose effect (CGI-Improvement score and BMI change $[\mathrm{r}=-0.46 ; p=0.004]$; CGI-Improvement score and EPS score $[\mathrm{r}=-0.42 ; p=0.009])$.

\section{DISCUSSION}

To the best of our knowledge, this is the first study to examine prospectively the link between clinical improvement and both NIMS and NIES in antipsychotic-naïve schizophrenia patients. In this study, we observed that greater the EPS and weight gain the greater was the clinical improvement. The study findings are in tune with the neuroleptic threshold hypothesis described earlier and also with earlier studies. The novel finding is the significant negative correlation between CGI-improvement and BMI suggesting the higher the weight gain the greater the improvement. The findings are in accord with earlier studies which had documented relation between weight gain and therapeutic response on posthoc or retrospective analysis. ${ }^{18)}$

Different theories have been proposed to explain the relation between metabolic side effects due to antipsychotics and clinical improvement. Insulin signalling pathway abnormalities have been proposed to explain the intriguing relation between the therapeutic efficacy and magnitude of metabolic disturbances. ${ }^{18)}$

Different studies have shown abnormalities in Insulin signalling pathway in schizophrenia. Though these could be secondary to antipsychotic treatment, insulin resistance has been reported even in the pre-neuroleptic era and antipsychotic-naïve schizophrenia patients were shown to have significantly increased insulin resistance. ${ }^{19,20)}$ Also in our earlier study, schizophrenia patients had a significantly higher plasma insulin level and mean insulin resistance scores but a lower plasma insulin-like growth factor-1 levels. ${ }^{21)}$ The mechanistic basis for the dopamine link being common to both NIMS and NIES is impressively elucidated in a comprehensive review. Insuling signalling system is linked with Akt/GSK pathways. It has been traditionally documented that dopamine receptors being associated with G-protein regulation and cyclic AMP/protein kinase A signalling. However recent developments have uncovered a cyclic AMP-independent mechanism of dopaminergic behaviors and signaling that involves Akt/GSK pathways at the D2 receptor. Dopamine transporter (DAT) knockout mice exhibit hyperactive behaviors and stereotypic movements. Interestingly, these DAT knockout mice demonstrated Akt/GSK abnormalities in their striatum that improved with dopamine depletion and by $\mathrm{D} 2$ receptor antagonism. It is noteworthy that inhibition of GSK-3 in DAT knockout mice also inhibited the dopamine-dependent behaviours. ${ }^{18)}$ These novel insights might explain the shared mechanistic basis for NIMS and NIES in schizophrenia and potentially offer the theoretical support to the concept of 'Neuro-Metabolic Threshold'.

It is important to note that evaluation of evidence for neuro-metabolic threshold in a naturalistic clinical study is difficult especially in context various potential confounding factors (duration and severity of clinical symptoms, inpatient or outpatient treatment, starting dosage and dose range of antipsychotics, evaluation of symptoms and titration method of antipsychotics, influence of other medications such as anticholinergics and benzodiazepines). Given this myriad of potential confounding variables, we consider that our modest attempt in elucidating such evidence is strengthened by the following methodological issues: evaluation of antipsychotic-naïve schizophrenia patients, analysing the patients who were treated uniformly with risperidone (as decided by the treating clinician); however, further studies need to address other potential confounding factors that could not be controlled in this study.

In conclusion, our study findings are in support of the possibility of a relation between antipsychotic induced adverse effects (NIMS and NIES) and therapeutic effects. Though the mechanism of this relation is yet to be eluci- 
dated, both receptor level and intracellular pathways may play a significant role. Abnormalities in dopamine system and insulin signalling pathway and their interactions may underlie both the pathogenesis and therapeutic effects of antipsychotics. However, the evidence to support the action of antipsychotic through insulin signalling pathway is preliminary and further studies are needed. In conclusion, there is a possibility of neurometabolic threshold with second generation antipsychotic treatment in schizophrenia, however further molecular studies are needed to ascertain a cut-off for metabolic threshold similar to neuroleptic threshold.

\section{Acknowledgments}

Partial support for the study was obtained from the Innovative Young Biotechnologist Award Grant to GV by the Department of Biotechnology, Government of India. SVK is supported by the Wellcome Trust/DBT India Alliance Research Grant to GV.

\section{REFERENCES}

1. Bitter I, Volavka J, Scheurer J. The concept of the neuroleptic threshold: an update. J Clin Psychopharmacol 1991;11: 28-33.

2. McEvoy JP. The neuroleptic threshold as a marker of minimum effective neuroleptic dose. Compr Psychiatry 1986;27: 327-335.

3. Kapur S, Zipursky R, Jones C, Remington G, Houle S. Relationship between dopamine D(2) occupancy, clinical response, and side effects: a double-blind PET study of first-episode schizophrenia. Am J Psychiatry 2000;157:514520.

4. Nordstrom AL, Farde L, Wiesel FA, Forslund K, Pauli S, Halldin C, et al. Central D2-dopamine receptor occupancy in relation to antipsychotic drug effects: a double-blind PET study of schizophrenic patients. Biol Psychiatry 1993;33: 227-235.

5. Farde L, Nordstrom AL, Wiesel FA, Pauli S, Halldin C, Sedvall G. Positron emission tomographic analysis of central D1 and D2 dopamine receptor occupancy in patients treated with classical neuroleptics and clozapine. Relation to extrapyramidal side effects. Arch Gen Psychiatry 1992; 49:538-544.

6. Stahl SM, Mignon L, Meyer JM. Which comes first: atypical antipsychotic treatment or cardiometabolic risk? Acta Psychiatr Scand 2009;119:171-179.
7. Bustillo JR, Buchanan RW, Irish D, Breier A. Differential effect of clozapine on weight: a controlled study. Am J Psychiatry 1996;153:817-819.

8. Leadbetter R, Shutty M, Pavalonis D, Vieweg V, Higgins P, Downs M. Clozapine-induced weight gain: prevalence and clinical relevance. Am J Psychiatry 1992;149:68-72.

9. Meltzer HY, Perry E, Jayathilake K. Clozapine-induced weight gain predicts improvement in psychopathology. Schizophr Res 2003;59:19-27.

10. Czobor P, Volavka J, Sheitman B, Lindenmayer JP, Citrome $\mathrm{L}$, McEvoy J, et al. Antipsychotic-induced weight gain and therapeutic response: a differential association. J Clin Psychopharmacol 2002;22:244-251.

11. Gupta S, Droney T, Al-Samarrai S, Keller P, Frank B. Olanzapine: weight gain and therapeutic efficacy. J Clin Psychopharmacol 1999;19:273-275.

12. Jones B, Basson BR, Walker DJ, Crawford AM, Kinon BJ. Weight change and atypical antipsychotic treatment in patients with schizophrenia. J Clin Psychiatry 2001;62 (Suppl 2):41-44.

13. Basson BR, Kinon BJ, Taylor CC, Szymanski KA, Gilmore JA, Tollefson GD. Factors influencing acute weight change in patients with schizophrenia treated with olanzapine, haloperidol, or risperidone. J Clin Psychiatry 2001;62:231238.

14. Sheehan DV, Lecrubier Y, Sheehan KH, Amorim P, Janavs $\mathrm{J}$, Weiller E, et al. The Mini-International Neuropsychiatric Interview (M.I.N.I.): the development and validation of a structured diagnostic psychiatric interview for DSM-IV and ICD-10. J Clin Psychiatry 1998;59(Suppl 20):22-33.

15. Andreasen NC. The Scale for the Assessment of Positive Symptoms (SAPS). Iowa City, IA:University of Iowa;1984.

16. Andreasen NC. The Scale for the Assessment of Negative Symptoms (SANS). Iowa City, IA: University of Iowa;1983.

17. Mohan V, Deepa R, Deepa M, Somannavar S, Datta M. A simplified Indian Diabetes Risk Score for screening for undiagnosed diabetic subjects. J Assoc Physicians India 2005;53:759-763.

18. Girgis RR, Javitch JA, Lieberman JA. Antipsychotic drug mechanisms: links between therapeutic effects, metabolic side effects and the insulin signaling pathway. Mol Psychiatry 2008;13:918-929.

19. Ryan MC, Collins P, Thakore JH. Impaired fasting glucose tolerance in first-episode, drug-naive patients with schizophrenia. Am J Psychiatry 2003;160:284-289.

20. Mukherjee S, Schnur DB, Reddy R. Family history of type 2 diabetes in schizophrenic patients. Lancet 1989;1:495.

21. Venkatasubramanian G, Chittiprol S, Neelakantachar N, Naveen MN, Thirthall J, Gangadhar BN, et al. Insulin and insulin-like growth factor-1 abnormalities in antipsychotic-naive schizophrenia. Am J Psychiatry 2007;164:15571560. 